\title{
Examination of the effect of preheating process on microtensile bond strength in the cementation of indirect restorations
}

\author{
Zuhal Görüş ${ }^{1}$ \\ ${ }^{1}$ Harran University, Faculty of Dentistry, Department of Prosthodontics, Şanlıurfa, Turkey
}

\section{Correspondence:}

\section{Dr. Zuhal GÖRÜş}

Harran University, Faculty of Dentistry, Department of Prosthodontics, Şanlıurfa, TURKEY.

E-mail:dtzuhal24 @hotmail.com

Received: 9 February 2018

Accepted: 16 March 2018

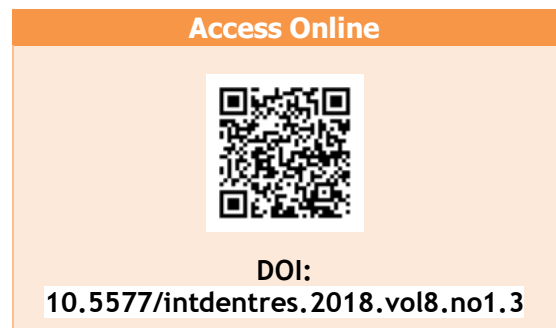

10.5577/intdentres.2018.vol8.no1.3

\section{Abstract}

Aim: The aim of this study was to investigate the effect of preheating of inlay and onlay restorations prepared from composite materials and using a CAD/CAM device on microtensile bond strength in different structures. Methodology: 90 impacted human third molar teeth were used. These teeth were divided into 3 groups. MOD inlay cavity preparation was performed. For the first group, restorations were prepared using a CAD/CAM device. For the second group, a fiber-reinforced composite (EverX Posterior, GC, Tokyo, Japan) was used and restoration was then completed using the laboratory composite system (Gradia, GC, Tokyo, Japan). For the third group, laboratory composite system (Gradia, GC, Tokyo, Japan) was used alone. Er,Cr:YSGG laser (Fotona Laser AT Fidelis Plus III, Slovenia) was administered on all prepared restorations. In the cementation of the restorations, resin cement was administered with and without preheating. The prepared samples were tested for microtensile bond strength (Microtensile Tester, Bisco, Schaumburg, IL, USA).

Results: There was no statistically significant difference between the groups of the microtensile bond strengths of the samples in which the adhesive cement was pre-heated $(P)$ and not pre-heated $(N)(p>0.05)$. There was a statistically significant difference $(p<0.05)$ in terms of the microtensile bond strength values between the groups in which the adhesive cement was pre-heated during the cementation of restorations. Conclusions: It was observed that exposure of the adhesive cement to preheating in the cementation of the EverX Posterior-based inlays adversely affects the bond strength. The preheating process statistically significantly increased the bond strength in the inlays made using the Gradia composite. Preheating of the cement in the cementation of Cerasmart composite inlays produced using the CAD/CAM system did not affect the microtensile bond strength.

Keywords: Preheating, CAD/CAM, microtensile, fiber-reinforced composite

How to cite this article: Görüş Z. Examination of the effect of preheating process on microtensile bond strength in the cementation of indirect restorations. Int Dent Res 2018;8(1):15-21. 


\section{Introduction}

Today, great interest is being paid to aesthetic restorations, and adhesive restoration materials are being explored extensively. They will allow the dentist to remove the minimum amount of material while following the basic cavity principles and to make restorations with better aesthetic, function and grip by strengthening the bonding of the restorations to the dental tissues (1-3).

The inlays can be prepared directly and indirectly. Only composite materials are used in the direct technique whereas both composites and porcelains can be used in the indirect technique $(4,5)$.

Composite restorative materials can be used as direct restoration materials or can also be used indirectly after preparation in the laboratory environment. The most important disadvantage of composite restorative materials is the shrinkage that occurs during their polymerization. The micro space and marginal mismatch resulting from this shrinkage are the factors that affect the success of the treatment negatively. Indirectly prepared composite restorations are a good alternate in order to ensure that the aforementioned shrinkage is minimized $(1,3,6)$.

CAD/CAM systems have gained an ergonomic structure appropriate for the clinical environment and the ability to offer material diversity. Restorations can be prepared in a single session and can be finished in the same session. These have increased the interest of patients in aesthetic restorations. The widespread use of these systems, which minimize loss of time and error margin, has also increased the number of treatment options available to the patient $(5,7,8)$.

In this study, it was aimed to guide dentists about the ideal treatment options for posterior aesthetics inlays by comparatively investigating the teeth restored using the laboratory and CAD/CAM inlays prepared from composite materials in different structures in terms of microtensile bond strength, and by testing the effectiveness of the preheating process, which can be done in order to strengthen the dental restoration bond.

\section{Materials and Methods}

In our study, 90 impacted human third molar teeth unaffected by the mouth environment were used. Whether there were any developmental defects or cracks in the crowns of the teeth was checked with a microscope (Leica M320, Leica Microsystems, Heerbrugg, Switzerland). The tissue residues on the teeth were removed using a periodontal curette, and the teeth were polished with pumice. The teeth were then disinfected by steeping in $0.1 \%$ thymol solution for one week at $+4{ }^{\circ} \mathrm{C}$. Afterwards, the teeth were kept in distilled water throughout the study.

To mimic the periodontal gap between the dental roots and the acrylic mold, the teeth were first wax-coated up to the level of crown. The teeth were then embedded in methacrylate resin molds. The process of embedding in resin molds was carried out as follows: A duplicate of the upper part of one of the 15x15×25 mm single hard drill boxes was created using silicone. Our sample was placed and fastened at the bottom of the hard drill box. Vaseline was applied to the bottom of the hard drill box and then embedded in clear acrylic (Vertex Orthoplast, Netherlands). The tooth in the acrylic mold was removed and stored in distilled water. The wax on the surfaces of the removed tooth was cleaned by lifting with the help of a dental sond. A type A silicone measurement material (Impregum Soft, 3M ESPE, Neuss, Germany) was placed in the acrylic molds prepared for each tooth, and it was made sure that the teeth were fastened.

MOD inlay cavity preparation was performed in all examples according to the parameters specified below.

Cavity depth: $2.5 \mathrm{~mm}$ from the center fossa

Cavity width: $3.0 \mathrm{~mm}$ buccolingually uniform

Gingival step depth: $1.5 \mathrm{~mm}$

Gingival step width: $1.0 \mathrm{~mm}$

All the cavities were prepared by a single clinician researcher using a dental loupe. For the preparation of all inlay cavities, a drill kit (Intensive Sevük-Ser Inlay/Onlay Kit, SS WHITE, Turkey) specially designed for inlays and onlays was used. The CAD-CAM digital scanning unit (DWOS, Dental Wings, Montreal, Canada) was used to provide a standard for the prepared inlay cavities.

30 samples were scanned using the CAD/CAM device scanning unit and transferred to the digital medium using the CEREC software. Again, using the CEREC software, 30 restorations were designed and made ready for production.

In our study, 60 samples, of which the preparations were completed, were set aside for their restorations to be produced in the laboratory. The dimensions of the samples were taken with a type A silicone measurement material. The measurements that were taken were sent without delay to a special laboratory (Ata Dental Laboratory, Gaziantep, Turkey) by shipping on the same day. All laboratory operations were carried out by a single technician. Dyes were prepared by casting plaster on the measurements in the laboratory. The prepared plaster dyes were divided into two groups of 30. A fiber-reinforced composite (EverX Posterior, GC, Tokyo, Japan) was used as the base material with a thickness of $1 \mathrm{~mm}$ on the bottom of the cavity to mimic dentin structure for one of the 
groups $(n=30)$. Both laboratory groups were restored using the same laboratory composite system (Gradia, GC, Tokyo, Japan).

Er,Cr:YSGG laser (Fotona Laser AT Fidelis Plus III, Slovenia) was administered on all prepared restorations for surface roughening, with a power of 20 W at a frequency of $10 \mathrm{~Hz}$ for 20 seconds.

After the roughening process, the next step was the cementation of restorations. In the cementation of the restorations, resin cement was administered with and without preheating. In the heating of the adhesive cement, the adhesive cement was heated to $50{ }^{\circ} \mathrm{C}$ using a special composite heating device (ENA Heat, Micerium SpA, Avegno GE, Italy). In the cementation of the remaining restorations nothing else was applied on the adhesive cement. All cementation procedures were performed at room temperature. After cementation, all samples were steeped in distilled water at $37{ }^{\circ} \mathrm{C}$ for 24 hours.

10 samples were set aside from each material group to test the microtensile bond strength. During the cementation, it was ensured that the adhesive cement was subjected to preheating in 5 of these samples, while the adhesive cement was not subjected to preheating in the other 5 . The prepared samples were placed in a microtensile tester, and the sticks were broken off by setting the loading speed at 1 $\mathrm{mm} / \mathrm{min}$. A digital compass was used to control the dimensions of sides of the sticks.

The prepared samples were tested for microtensile bond strength (Microtensile Tester, Bisco, Schaumburg, IL, USA). The results obtained in Newtons were divided into the surface area and converted to $\mathrm{MPa}$. The results were recorded as microtensile bond strength values.

\section{Statistical Analysis}

SPSS 15.0 Windows computer package program was used to evaluate the data obtained in the study. One-way analysis of variance (One Way Anova) was used in the comparison of group means because there were more than two groups. The Duncan test was administered as a multiple comparison test. The $t$ test was used for the comparison of heat applications.

\section{Results}

The microtensile bond strength means, standard deviations, minimum values, maximum values and $F$ and $P$ values related to these values that were obtained in all groups were as indicated in Table 1. In the comparison between the experimental groups, the highest mean microtensile bond strength value was found in the G-P group (the group in which preheating was administered during the cementation of restorations, in the restoration group restored using the Gradia posterior indirect composite material). The lowest mean microtensile bond strength was achieved in the CC-P group (the group in which preheating was administered during the cementation of restorations, in the restoration group restored using the CAD/CAM system). It was determined that there was a significant difference in the statistical analysis based on microtensile bond strength values between the groups $(\mathrm{p}<0.01)$ (Table 1).

There was no statistically significant difference between the groups in terms of the statistical evaluation of the microtensile bond strengths of the samples in which the adhesive cement was pre-heated $(\mathrm{P})$ and not pre-heated $(\mathrm{N})$ during the cementations $(p>0.05)$. When the microtensile bond strength values of the groups were examined, it was observed that the mean microtensile bond strength value of the negative group was higher (Table 2).

There was a statistically significant difference $(p<0.05)$ in terms of the microtensile bond strength values between the groups in which the adhesive cement was not pre-heated (CC-N, EG-N, G-N) during the cementation of restorations. When the mean microtensile bond strength values were compared between the groups, it was seen that the EG-N group had a higher mean microtensile bond strength value. The lowest bond strength was observed in the CC-N group (Table 3).

There was a statistically significant difference $(p<0.01)$ in terms of the microtensile bond strength values between the groups in which the adhesive cement was pre-heated (CC-P, EG-P, G-P) during the cementation of restorations. When the mean microtensile bond strength values between the groups were compared, the G-P group had the highest mean bond strength value, and the lowest mean bond strength value belonged to the CC-P group (Table 4).

In the group restored using the CAD/CAM system, there was no statistically significant difference $(p>0.05)$ between the group in which preheating was not administered (CC-N) and the group in which preheating was administered (CC-P) during the cementation of restorations in terms of fracture resistance values. When the mean microtensile bond strength values were compared between the groups, it was seen that the $\mathrm{CC}-\mathrm{N}$ group had a higher bond strength value (Table 5 ).

In the group restored using the EverX-Gradia composite materials, there was no statistically significant difference $(p>0.05)$ between the group in which preheating was not administered (EG-N) and the 
group in which preheating was administered (EG-P) during the cementation of restorations in terms of fracture resistance values. When the mean bond strength values were compared between the groups, it was seen that the EG-N group had a higher mean bond strength value (Table 6).

In the group restored using the Gradia posterior indirect composite material, there was a statistically significant difference $(p<0.05)$ between the group in which preheating was not administered (G-N) and the group in which preheating was administered (G-P) during the cementation of restorations in terms of the microtensile bond strength values. When the mean bond strength values were compared between the groups, it was seen that the G-P group had a higher mean bond strength value (Table 7).

Table 1. Microtensile Bond Strength Values

\begin{tabular}{|c|c|c|c|c|c|c|c|}
\hline \multirow[b]{2}{*}{ Groups } & \multicolumn{5}{|c|}{ Descriptive Statistics } & \multicolumn{2}{|c|}{ ANOVA } \\
\hline & $\mathbf{n}$ & $\begin{array}{l}\text { Mean } \\
\text { Value }\end{array}$ & $\begin{array}{l}\text { Standard } \\
\text { Deviation }\end{array}$ & Min. & Max. & F value & $p$ value \\
\hline $\mathrm{CC}-\mathrm{N}$ & 15 & $10.93^{C}$ & 3.006 & 6.40 & 17.20 & \multirow{6}{*}{6.86} & \multirow{6}{*}{$<0.0001$} \\
\hline CC-P & 15 & $10.80^{C}$ & 3.00 & 3.20 & 15.60 & & \\
\hline EG-N & 15 & $17.45 \mathrm{~A}, \mathrm{~B}$ & 6.23 & 8.40 & 28.80 & & \\
\hline EG-P & 15 & $15.40^{\mathrm{B}}$ & 5.53 & 6.80 & 26.40 & & \\
\hline G-N & 15 & $13.86^{B, C}$ & 6.70 & 8.00 & 35.20 & & \\
\hline G-P & 15 & $20.30^{\mathrm{A}}$ & 7.04 & 11.20 & 31.20 & & \\
\hline
\end{tabular}

CC-N: The group in which preheating was not administered during the cementation of restorations, in the restoration group restored using the CAD/CAM system

CC-P: The group in which preheating was administered during the cementation of restorations, in the restoration group restored using the CAD/CAM system

EG-N: The group in which preheating was not administered during the cementation of restorations, in the restoration group restored using the EverX-Gradia posterior composite materials

EG-P: The group in which preheating was administered during the cementation of restorations, in the restoration group restored using the EverX-Gradia posterior composite materials

G-N: The group in which preheating was not administered during the cementation of restorations, in the restoration group restored using the Gradia posterior composite materials

G-P: The group in which preheating was administered during the cementation of restorations, in the restoration group restored using the Gradia posterior composite materials

Table 2. Microtensile bond strength values between the groups in which preheating was administered and not administered

\begin{tabular}{cccc|c|c|}
\hline & \multicolumn{3}{c}{ Descriptive Statistics } & \multicolumn{2}{c|}{ t test } \\
GROUPS & $\mathrm{n}$ & Mean & $\begin{array}{c}\text { Standard } \\
\text { Deviation }\end{array}$ & t value & P value \\
\hline Negative (N) & 45 & $15.502^{\mathrm{A}}$ & 0.9061 & -1.06 & 0.2928 \\
\hline Positive (P) & 45 & $14.084^{\mathrm{A}}$ & 0.9867 & & \\
\hline
\end{tabular}

Table 3. Statistical evaluation of the groups between each other in which preheating was not administered

\begin{tabular}{cccccc} 
& \multicolumn{3}{c}{ Descriptive Statistics } & \multicolumn{2}{c}{ t test } \\
GROUPS & $\mathrm{n}$ & Mean & $\begin{array}{l}\text { Standard } \\
\text { Deviation }\end{array}$ & t value & p value \\
\hline CC-N & 15 & $10.93^{\mathrm{B}}$ & 3.06 & & \\
EG-N & 15 & $17.45^{\mathrm{A}}$ & 6.23 & 5.14 & 0.010 \\
\hline G-N & 15 & $13.86^{\mathrm{A}, \mathrm{B}}$ & 6.70 & & \\
\hline
\end{tabular}


Table 4. Statistical evaluation of the groups in which preheating was administered during their cementations

\begin{tabular}{cccccc} 
& \multicolumn{3}{c}{ Descriptive Statistics } & \multicolumn{2}{c}{ t test } \\
GROUPS & $\mathrm{n}$ & Mean & $\begin{array}{l}\text { Standard } \\
\text { Deviation }\end{array}$ & t value & p value \\
CC-P & 15 & $10.80^{\mathrm{C}}$ & 3.00 & \\
EG-P & 15 & $15.40^{\mathrm{B}}$ & 5.53 & 11.40 & 0.0001 \\
G-P & 15 & $20.30^{\mathrm{A}}$ & 7.04 & & \\
\hline
\end{tabular}

Table 5. Statistical evaluation of the microtensile bond strength values of the sub-groups in the CAD/CAM group in which heat was administered and not administered during the cementations

\begin{tabular}{|c|c|c|c|c|c|}
\hline & \multicolumn{3}{|c|}{ Descriptive Statistics } & \multicolumn{2}{|l|}{$\mathrm{t}$ test } \\
\hline GROUPS & $\mathrm{n}$ & Mean & $\begin{array}{l}\text { Standard } \\
\text { Deviation }\end{array}$ & $\mathrm{t}$ value & p value \\
\hline CC-N & 15 & $10.93 \mathrm{~A}$ & 3.06 & \multirow[b]{2}{*}{0.12} & \multirow[b]{2}{*}{0.9051} \\
\hline CC-P & 15 & $10.80^{A}$ & 3.00 & & \\
\hline
\end{tabular}

Table 6. Statistical evaluation of the microtensile bond strength values of the sup-groups in the EverX-Gradia group in which heat was administered and not administered during the cementations

\begin{tabular}{cccccc} 
& \multicolumn{3}{c}{ Descriptive Statistics } & \multicolumn{2}{c}{ t test } \\
GROUPS & $\mathrm{n}$ & Mean & $\begin{array}{c}\text { Standard } \\
\text { Deviation }\end{array}$ & t value & $\mathrm{p}$ value \\
EG-N & 15 & $17.45 \mathrm{~A}$ & 6.23 & & \\
EG-P & 15 & $15.40 \mathrm{~A}$ & 5.53 & & 0.95 \\
\hline
\end{tabular}

Table 7. Statistical evaluation of the microtensile bond strength values of the sup-groups in the Gradia group in which heat was administered and not administered during the cementations

\begin{tabular}{cccccc} 
& \multicolumn{3}{c}{ Descriptive Statistics } & \multicolumn{2}{c}{ t test } \\
GROUPS & $\mathrm{n}$ & Mean & $\begin{array}{l}\text { Standard } \\
\text { Deviation }\end{array}$ & t value & P value \\
\hline G-N & 15 & $13.86 \mathrm{~A}$ & 6.70 & -2.56 & 0.0160 \\
\hline G-P & 15 & $20.30 \mathrm{~A}$ & 7.04 & & \\
\hline
\end{tabular}




\section{Discussion}

Patients' desire for natural and healthy appearance, awareness of allergic and toxic substances, and the increase in their aesthetic expectations for the posterior regions as well as the anterior regions have brought forward the composite inlays $(8,10)$. Inlay and onlay restorations are among the aesthetic restorative treatment options that are preferred in the posterior region and require minimal preparation. Aesthetic composite restorative materials can be used as direct restoration materials or can also be used indirectly after preparation in the laboratory environment $(4,6,16)$.

It is suggested that the disadvantages of direct composite restorations can be eliminated by indirect inlay applications in the light of the research studies $(2,3,15)$. Considering recent developments in adhesive and indirect composite materials, different types of indirect composite inlay groups were included in our study.

A variety of studies are available on composites with fiber content, which are a recent material. In studies on many base composites that have been proposed to imitate dentin to give durability and resilience to restoration, the bending strength of EverX Posterior composite was found to be higher than that of others $(13,14)$. EverX Posterior was used as a base material in a group of our study in the light of these research results.

In order to improve the physical achievements of composite restorations as well as their aesthetic achievements, preheating with various devices is a method that has been applied in recent years and is said to be successful $(12,18)$. Preheating improves the penetration ability of the composite material by decreasing its viscosity and reduces the risk of secondary caries (11).

A study by Wagner et al. showed a significant difference between groups in which preheating was administered (17). These results partially parallel our study. In our study, the preheating process increased the bond significantly only in the G-P group.

Cantoro et al. have reported in one of their studies that preheating the samples increases the microtensile bond strength (7). As a result of our study, the EG-N group gave the highest bond value among the groups in which preheating was not administered, while there was a decrease in the bond values after the preheating process. We think that the preheating of the resin cement in the EG-N inlay group breaks down the fiber structure, and thus the bond values are reduced. It was observed that the preheating process statistically significantly increased the bond strength in the inlays made using $\mathrm{G}-\mathrm{N}$.

Studies have shown that preheating the composite does not have a positive effect on the composite flexural strength and polymer crossbonding, but enhances marginal adaptation $(5,9)$. As is known, the fracture-related properties of the material can be evaluated by determining the parameters of flexural strength and flexural modulus. Therefore, the fact that the flexural strength was not increased indicates that there was no positive effect on the physical properties of the material. The bond strength values of the groups in which preheating was administered were found to be lower in our study, too $(p>0.05)$.

Morais et al. have reported in their study that the effectiveness of preheating depends on the product used (1). Paralleling that study, it was also found in our study that preheating of the cement in the cementation of Cerasmart composite inlays produced using the CAD/CAM system did not affect the microtensile bond strength.

\section{Conclusions}

1- It was observed that exposure of the adhesive cement to preheating in the cementation of the EverX Posterior-based inlays adversely affected the bond strength.

2- It was observed that the preheating process statistically significantly increased the bond strength in the inlays made using the Gradia composite.

3- Preheating of the cement in the cementation of Cerasmart composite inlays produced using the CAD/CAM system did not affect the microtensile bond strength.

Ethical Approval: Ethics committee approval was received for this study from Harran University, Faculty of Medicine.

Peer-review: Externally peer-reviewed.

Author Contributions: Conception - Z.G.; Design -Z.G.; Supervision - Z.G.; Materials - Z.G.; Data Collection and/or Processing - Z.G.; Analysis and/or Interpretation - Z.G.; Literature Review - Z.G.; Writer - Z.G.; Critical Review Z.G.

Conflict of Interest: No conflict of interest was declared by the authors.

Financial Disclosure: The authors declared that this study has received no financial support. 


\section{References}

1. Morais A, Santos A, Giannini M, Reis AF, Rodrigues JA, Arrais CAG. Effect of pre-heated dual-cured resin cements on the bond strength of indirect restorations to dentin. $\mathrm{Br}$ Oral Research 2012;26:170-6. [Crossref]

2. Sezgin Bolgül B, Ağaçkıran E, Tümen EC, Ayna Y, Çelenk S, Ayna B. Emergency Aesthetic Approaches to Patients with Body Dysmorphic Disorder: Report of Three Cases. Int Dent Res 2011;3:87-91. [Crossref]

3. Cangul S, Adiguzel 0 . The latest developments related to composite resins. Int Dent Res 2017;7:32-41. [Crossref]

4. Pegoraro TA, da Silva NR, Carvalho RM. Cements for use in esthetic dentistry. Dent Clin North Am 2007;51(2):453-71. [Crossref]

5. Lohbauer U, Zinelis S, Rahiotis C, Petschelt A, Eliades G. The effect of resin composite pre-heating on monomer conversion and polymerization shrinkage. Dent Mater 2009;25:514-9. [Crossref]

6. Deb S, Di Silvio L, Mackler HE, Millar BJ. Pre-warming of dental composites. Dent Mater 2011;27(4):51-9. [Crossref]

7. Cantoro A, Goracci C, Papacchini F, Mazzitelli C, Fadda GM, Ferrari M. Effect of pre-cure temperature on the bonding potential of self-etch and self-adhesive resin cements. Dent Mater 2008;24(5):577-83. [Crossref]

8. Sümer E, Değer Y. Contemporary Permanent Luting Agents Used in Dentistry: A Literature Review. Int Dent Res 2011;1:2631. [Crossref]

9. Lovell LG, Newman SM, Bowman CN. The effects of light intensity, temperature and comonomer composition on the polymerization behavior of dimethacrylate dental resins. J Dent Res 1999;78:1469-76. [Crossref]

10. Daronch M, Reuggeberg FA, Moss L, Goes MF. Clinically relevant issues related to preheating composities. J Esthet Restor Dent 2006;18:340-50. [Crossref]

11. Lucey S, Lynch CD, Ray NJ, Burke FM, Hannigan A. Effect of pre-heating on the viscosity and microhardness of a resin composite. J Oral Rehabil 2010:37: 278-82. [Crossref]

12. Gönülol N, Karaman E. Polimerizasyon öncesi ısıtma ișleminin kompozit rezinlerde renk değişimine etkisi. J Cumhuriyet Dent 2013;16:110-5. [Crossref]

13. Goracci C, Cadenaro M, Fontanive L, Giangrosso G, Juloski J, Vichi A, Ferrari, M. Polymerization efficiency and flexural strength of low-stress restorative composites. Dent Mater2014; 30:688-94. [Crossref]

14. Abouelleil H, Pradelle N, Villat C, Attik N, Colon P, Grosgogeat B. Comparison of mechanical properties of a new fiber reinforced composite and bulk filling composites. Rest Dent\&Endodontics, 2015;40:262-70. [Crossref]

15. Fonseca RG, Santos JG, Adabo GL. Influence of activation modes on diametral tensile strength of dual-curing resin cements. Braz Oral Res 2005;19(4):267-71. [Crossref]

16. El-Mowafy OM, Rubo MH. Influence of composite inlay/onlay thickness on hardening of dual-cured resin cements. J Can Dent Assoc 2000;66(3): 147.

17. Oskoee PA, Nooroloyouni A, Azar FP, Ashraf AP. Effect of Resin Cement Pre-heating on the Push-out Bond Strength of Fiber Post to Root Canal Dentin. J Dent Res Dent Clin Dent Prospects 2015;9(4):233-8. [Crossref]

18. Wagner WC, Aksu MN, Neme AM, Linger JB, Pink FE, Walker S. Effect of pre-heating resin composite on restoration microleakage. Oper Dent 2008;33(1):72-8. [Crossref] 